Review

\title{
Biophysical Properties of Lumbricus terrestris Erythrocruorin and Its Potential Use as a Red Blood Cell Substitute
}

\author{
Jacob Elmer and Andre F. Palmer * \\ William G. Lowrie Department of Chemical and Biomolecular Engineering, The Ohio State \\ University, 425 Koffolt Laboratories, 140 West 19th Avenue, Columbus, OH 43210, USA; \\ E-Mail: elmer.18@osu.edu
}

* Author to whom correspondence should be addressed; E-Mail: palmer.351@osu.edu; Tel.: +614-292-6033.

Received: 21 October 2011; in revised form: 9 December 2011 / Accepted: 24 December 2011 / Published: 6 January 2012

\begin{abstract}
Previous generations of hemoglobin (Hb)-based oxygen carriers (HBOCs) have been plagued by key biophysical limitations that result in severe side-effects once transfused in vivo, including protein instability, high heme oxidation rates, and nitric oxide (NO) scavenging. All of these problems emerge after mammalian Hbs are removed from red blood cells (RBCs) and used for HBOC synthesis/formulation. Therefore, extracellular Hbs (erythrocruorins) from organisms which lack RBCs might serve as better HBOCs. This review focuses on the erythrocruorin of Lumbricus terrestris ( $\mathrm{LtEc}$ ), which has been shown to be extremely stable, resistant to oxidation, and may interact with NO differently than mammalian Hbs. All of these beneficial properties show that LtEc is a promising new HBOC which warrants further investigation.
\end{abstract}

Keywords: red blood cell substitute; hemoglobin; erythrocruorin; oxygen carrier

\section{Extracellular Hemoglobins: A New Paradigm}

As of 2011, the only hemoglobin ( $\mathrm{Hb}$ ) based oxygen carriers (HBOCs) that have entered phase III clinical trials are polymerized human [1-4] and bovine [5-8] $\mathrm{Hb}$ (PolyHb) as well as poly(ethylene glycol) surface-conjugated human hemoglobin (MP4, Sangart Inc., San Diego, CA, USA) [9-12]. MP4 is currently undergoing clinical trials, but the PolyHbs have been discontinued due to indications of 
increased mortality and other complications [13]. The major problems associated with these HBOCs (instability, oxidative stress, and nitric oxide (NO) scavenging) can be directly attributed to removing $\mathrm{Hb}$ from the protective environment within the red blood cell (RBC). The $\mathrm{RBC}$ has enzymes to prevent oxidation [14-16], a cell membrane to reduce interactions with NO [17], allosteric effectors to modulate $\mathrm{O}_{2}$ delivery [18], and high $\mathrm{Hb}$ concentrations that minimize dimerization of the $\mathrm{Hb}$ tetramer [19].

Since mammalian Hbs purified from RBCs are burdened with so many problems, extracellular Hbs from other organisms may be better suited for use in HBOC development. This special class of Hbs, known as erythrocruorins (Ecs), are found in organisms which lack RBCs (most annelids [20], some mollusks [21] and insects [22]). Consequently, Ecs have already adapted to the harsh conditions in the bloodstream with unique structural and functional modifications that make them attractive natural HBOCs. This review will focus on the unique properties of Ec from the Earthworm Lumbricus terrestris (LtEc).

\section{Structure and Stability of LtEc}

Ecs come in a wide variety of shapes and sizes, including the spherical Ec of Riftia pachyptila $(\sim 400 \mathrm{kDa})$ [23], the hexagonal bilayer (HBL) Ecs of L. terrestris [24] or Arenicola marina [25], and the huge cylindrical Ec of the clam Cardita borealis (12 MDa) [26]. These Ecs are all held together by covalent disulfide bonds and strong electrostatic or hydrophobic forces within large subunit interfaces. Therefore, they are not susceptible to dissociation at low concentrations like mammalian Hbs, which lack intermolecular disulfide bonds [27].

LtEc consists of a macromolecular assembly of 144 globin subunits and 36 linker chains (Figure 1) $[24,28,29]$. There are 5 types of globins $\left(A, B, C\right.$, and $D_{1}$ or $D_{2}$ ) [30,31] and 4 types of linkers (L1, L2, L3, and L4) [32,33]. Each globin subunit has a single intramolecular disulfide bond and a structure that is more similar to myoglobin than mammalian $\mathrm{Hb}$ subunits [28]. Each subunit also contains a heme group, which binds oxygen $\left(\mathrm{O}_{2}\right)$ and even contributes to subunit association by forming hydrogen bonds with adjacent subunits through propionate groups [29]. The A, B, and C subunits also have intermolecular disulfide bonds which form an $\mathrm{ABC}$ trimer. The $\mathrm{ABC}$ trimer and $\mathrm{D}$ monomer self-associate through electrostatic and hydrophobic interactions to form the $\mathrm{ABCD}$ tetramer [34]. Next, the $A_{3} B_{3} C_{3} D_{3}$ dodecamer spontaneously forms from three $A B C D$ tetramers through disulfide bonds. The dodecamer is hemi-spherical and has a structure that is reminiscent of the spherical (double dodecamer) Ec of $R$. pachyptila (RpEc) or Oligobrachia mashikoi (OmEc), suggesting that LtEc may have also been spherical at some point during its evolution $[23,35,36]$.

The linker chains are not required for dodecamer formation [37], but they are necessary to form the complete hexagonal bilayer structure of LtEc. Initially, three linker chains self-assemble to form a linker trimer. The linker chains are degenerate, meaning that several combinations of $\mathrm{L}_{1}, \mathrm{~L}_{2}, \mathrm{~L}_{3}$ or $\mathrm{L}_{4}$ can create the trimer. In fact, the minimum requirement for linker trimer formation is only a binary mixture of $\mathrm{L}_{1}$ or $\mathrm{L}_{2}$ with $\mathrm{L}_{3}$ or $\mathrm{L}_{4}$ [37]. The purpose and origin of the degeneracy in the linker and globin subunits are not known and any possible effects of different subunit compositions will need to be considered in future studies. The linker trimer is held together by numerous disulfide bonds and strong hydrophobic interactions within a coiled coil domain [24]. The linker trimer also has large low density lipoprotein (LDL) domains which strongly bind the dodecamer to form the protomer. Finally, 
12 protomers assemble through interactions between the coiled coil domains of the linker trimers to form the hexagonal bilayer structure of LtEc, which has a molecular weight (MW) of approximately 3.6 MDa and a diameter of $30 \mathrm{~nm}$ as shown in Table 1 [24]. To put these numbers into context, human $\mathrm{Hb}(\mathrm{HbA})$ has a MW of $0.064 \mathrm{MDa}$ and a diameter of $5 \mathrm{~nm}$ [27].

Figure 1. Assembly of Lumbricus terrestris erythrocruorin ( $\mathrm{LtEc})$. LtEc consists of 5 globin subunits $\left(A, B, C, D_{1}{ }^{\prime}\right.$, and $\left.\mathrm{D}_{2}\right)$ and 4 linker chains $\left(\mathrm{L}_{1}, \mathrm{~L}_{2}, \mathrm{~L}_{3}\right.$, or $\left.\mathrm{L}_{4}\right)$. The subunits self assemble into an $\mathrm{ABC}$ trimer that pairs with a $\mathrm{D}$ monomer to form the $\mathrm{ABCD}$ tetramer which then associates with two more tetramers to form the dodecamer. Three linker subunits form a linker trimer which binds the dodecamer to form a protomer. Finally, 12 protomers assemble into the hexagonal bilayer structure of LtEc, which has a MW of 3.6 MDa and a diameter of approximately $30 \mathrm{~nm}$ [24]. HbA [27] and myoglobin $(\mathrm{Mb})[38]$ are shown to the right to provide a sense of scale.

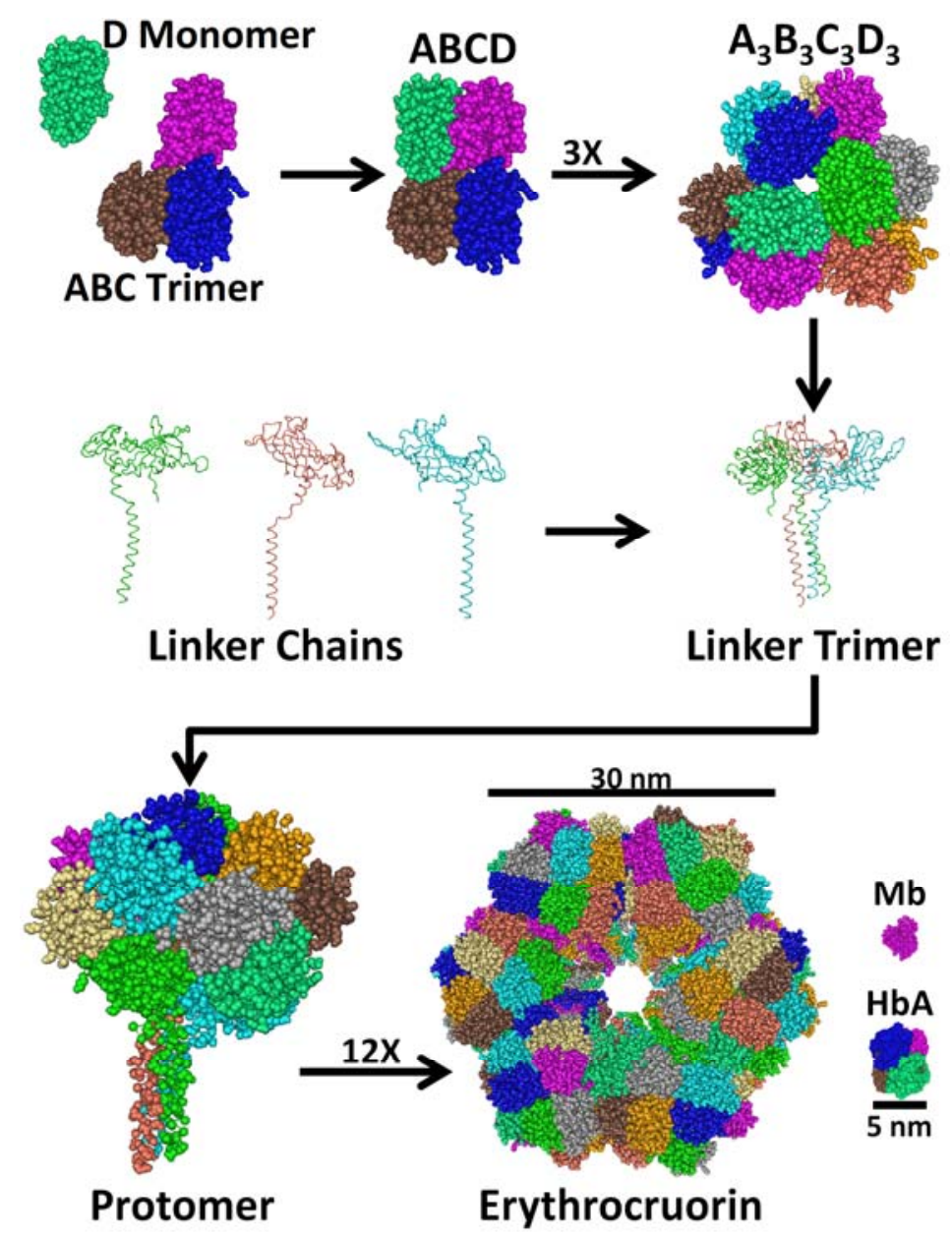

Table 1. Size, molecular weight $(\mathrm{MW}), \mathrm{O}_{2}$ affinity $\left(\mathrm{P}_{50}\right)$, and cooperativity (calculated as the constant $n$ from the Hill Equation) of HbA, AmEc, LtEc, and human RBCs.

\begin{tabular}{ccccc}
\hline & MW (kDa) & Diameter $(\mathbf{n m})$ & $\mathbf{P}_{\mathbf{5 0}}(\mathbf{m m} \mathbf{H g})$ & $\boldsymbol{n} \mathbf{( - - - )}$ \\
\hline $\mathrm{HbA}$ & 64 & 5 & 11 & 2.7 \\
$\mathrm{AmEc}$ & $3,600[39]$ & $30[39]$ & 2.6 & $2.5[39]$ \\
$\mathrm{LtEc}$ & 3,600 & 30 & $28[40]$ & 3.7 \\
$\mathrm{RBC}$ & --- & 8,000 & $26[41]$ & $2.75[41]$ \\
\hline
\end{tabular}


Several other elements also contribute to the structure of LtEc. Approximately 50 calcium ions $\left(\mathrm{Ca}^{2+}\right)$ are bound at various sites throughout LtEc. Copper and zinc atoms are also bound to LtEc [42]. The $\mathrm{Ca}^{2+}$ ions increase the stability of LtEc and help it resist unfolding at high temperatures $[34,43]$. Barium $\left(\mathrm{Ba}^{2+}\right)$ has similar effects and addition of EDTA (which chelates divalent cations) decreases the thermal stability of LtEc [43]. LtEc is also extremely stable in the presence of chemical denaturants, exhibiting a half-life of 28 hours in $1.75 \mathrm{M}$ urea [34]. However, LtEc is prone to subunit dissociation at alkaline $\mathrm{pH}(>8.0)$ [44]. In the oxidized $\left(\mathrm{Fe}^{3+}\right)$ form, LtEc is also susceptible to higher rates of hemin release than oxidized $\mathrm{HbA}\left(\mathrm{LtEc}=20-40 \times 10^{-3} \mathrm{~min}^{-1}, \mathrm{HbA}=7.7 \times 10^{-3} \mathrm{~min}^{-1}\right)[45]$. It is important to mention that some Ecs may be unstable in vivo. For example, the marine worm $A$. marina expresses an $\mathrm{Ec}(\mathrm{AmEc})$ which is adapted to a high ionic strength and quickly dissociates into dodecamers in human plasma, which has relatively low ionic strength [39]. In contrast, LtEc comes from the terrestrial Earthworm and is stable at the ionic strength of human blood [40].

\section{3. $\mathrm{O}_{2}$ Transport by LtEc}

Human blood and LtEc bind and release $\mathrm{O}_{2}$ in a similar fashion (see Table 1). The $\mathrm{O}_{2}$ affinity or $\mathrm{P}_{50}$ $\left(\mathrm{pO}_{2}\right.$ at which half of the hemes are saturated with $\mathrm{O}_{2}$ ) of human blood $(26 \mathrm{~mm} \mathrm{Hg}$ ) is almost identical to LtEc (28 mm Hg) [40]. This is in contrast to pure $\mathrm{HbA}$ and AmEc, which both have significantly lower $\mathrm{P}_{50}$ values (higher $\mathrm{O}_{2}$ affinities) than human blood. The $\mathrm{O}_{2}$ affinity of $\mathrm{HbA}$ decreases when it is purified from human blood due to the removal of its allosteric effector 2,3-DPG [18]. The allosteric effector of $\mathrm{LtEc}$ is $\mathrm{Ca}^{2+}$, which increases the $\mathrm{O}_{2}$ affinity of $\mathrm{LtEc}$ and is available in the bloodstream. Other divalent cations, like $\mathrm{Ba}^{2+}, \mathrm{Sr}^{2+}$, and $\mathrm{Mg}^{2+}$, have a similar effect on the $\mathrm{O}_{2}$ affinity of $\mathrm{LtEc}[46,47]$. The relatively high $\mathrm{O}_{2}$ affinity (low $\mathrm{P}_{50}$ ) of AmEc is probably another effect of its exposure to low ionic strength buffers or an adaptation to the low $\mathrm{O}_{2}$ environment in which A. marina is found [39].

Cooperative oxygen binding is a unique trait of $\mathrm{Hbs}$ in which small changes in one subunit (i.e., ligand binding) affect the conformations and ligand affinities of adjacent subunits. This phenomenon allows $\mathrm{Hbs}$ to become saturated with $\mathrm{O}_{2}$ in the lungs, hold onto it in the arteries, then release it in large amounts in the arterioles and capillaries. The cooperativities of HbA, AmEc, and blood are all around 2.5-2.7 under physiological conditions. The cooperativity of LtEc is relatively higher under physiological conditions (3.7), due to the increased number of subunit interactions within the LtEc dodecamer. In fact, the maximum cooperativity of $\mathrm{LtEc}$ is 7.9 at $25^{\circ} \mathrm{C}$ and $\mathrm{pH} 7.7$ with $25 \mathrm{mM} \mathrm{CaCl}_{2}$ [48]. The effects of cooperativity also appear to be mostly within the dodecamers and only slightly (if at all) transmitted between dodecamers [49].

As previously mentioned, the LtEc dodecamer spontaneously forms in the absence of the linker chains. Interestingly, isolated dodecamers and $\mathrm{ABCD}$ tetramers have $\mathrm{O}_{2}$ affinities and cooperativities similar to LtEc in its full form. The isolated $\mathrm{ABC}$ trimer and $\mathrm{D}$ monomer, however, have significantly higher $\mathrm{O}_{2}$ affinities and lower cooperativities. Therefore, the linker chains are not required for $\mathrm{O}_{2}$ transport and appear to simply increase the stability and size of LtEc [49].

\section{Autoxidation of LtEc}

Oxidation of the heme iron $\left(\mathrm{Fe}^{2+} \rightarrow \mathrm{Fe}^{3+}\right)$ is an inevitable side-effect of $\mathrm{O}_{2}$ transport for all Hbs. After $\mathrm{O}_{2}$ binds to the heme iron, it can strip away an electron and escape the heme pocket, forming the 
pro-oxidant superoxide $\left(\mathrm{O}_{2}{ }^{-}\right)$and oxidized $\mathrm{Hb}$ (metHb, $\mathrm{Fe}^{3+}$ ). MetHb can be further oxidized to the ferryl form $\left(\mathrm{Fe}^{4+}\right)$ and/or generate toxic hemichrome and other free radicals which greatly increase lipid oxidation in cell membranes and overall oxidative stress [50]. The size, structure, and amino acid composition of the heme pocket all have significant effects on the rate of $\mathrm{Hb}$ autoxidation. Large heme pockets allow $\mathrm{O}_{2}{ }^{-}$to easily escape $[51,52]$, while aromatic amino acids (i.e., tyrosine or phenylalanine) within the heme pocket stabilize $\mathrm{O}_{2}{ }^{-}$and reduce oxidation rates [52].

The heme pockets of $\mathrm{LtEc}$ are much smaller than $\mathrm{HbA}$ heme pockets [24,27]. Each subunit of LtEc also has phenylalanine or tryptophan residues which are not present in the heme pockets of $\mathrm{HbA}$ subunits [24]. These differences are clearly expressed in the redox potentials of HbA and LtEc (see Table 2). The redox potential of a species is a measure of how likely it is to accept or donate electrons. Species with positive redox potentials are more likely to accept electrons (reduction), while negative redox potentials indicate that a species is more likely to donate electrons (oxidation). The redox potential of $\mathrm{HbA}$ is negative $(-50 \mathrm{mV})$, whereas $\mathrm{LtEc}$ has a highly positive redox potential $(+112 \mathrm{mV})$. Therefore, LtEc is much less likely to undergo autoxidation than $\mathrm{HbA}$ [53-55]. In fact, experiments have shown that the autoxidation rate of $\mathrm{LtEc}\left(<0.010 \mathrm{~h}^{-1}\right)$ is lower than $\mathrm{HbA}$ $\left(0.014 \mathrm{~h}^{-1}\right)$ [53]. LtEc may also be reduced by reducing agents that are found in the bloodstream (ascorbic acid or glutathione), while $\mathrm{HbA}$ is not as easily reduced [53,54].

Table 2. Autoxidation rates and redox potentials of $\mathrm{HbA}, \mathrm{LtEc}$, and AmEc.

\begin{tabular}{ccc}
\hline & $\mathbf{k}_{\mathbf{0 x}}\left(\mathbf{h}^{-\mathbf{1}}\right)$ & $\mathbf{E}_{\mathbf{0}} \mathbf{( m \mathbf { ~ } )}$ \\
\hline $\mathrm{HbA}$ & $0.014[39]$ & $-50[53]$ \\
$\mathrm{LtEc}$ & $\leq 0.010$ & $+112[53]$ \\
$\mathrm{AmEc}$ & $0.005[56]$ & $+63[53]$ \\
\hline
\end{tabular}

Divalent cations also influence oxidation of $\mathrm{LtEc}$. For example, $\mathrm{Ba}^{2+}$ and $\mathrm{Ca}^{2+}$ both reduce the rate of LtEc autoxidation. $\mathrm{Sr}^{2+}$ and $\mathrm{Mg}^{2+}$ have a similar, yet less significant effect [43]. The $\mathrm{Cu}$ and $\mathrm{Zn}$ atoms which are bound to LtEc also appear to have some superoxide dismutase (SOD) activity. SODs are a family of enzymes which react with $\mathrm{O}_{2}{ }^{-}$to form water, thereby preventing formation of harmful $\mathrm{H}_{2} \mathrm{O}_{2}$ from $\mathrm{O}_{2}^{-}$. The SOD activity of LtEc is approximately $10 \%$ of the human SOD enzyme, but any intrinsic anti-oxidant activity is beneficial from an HBOC development perspective [57].

\section{Interactions Between LtEc and other Ligands}

$\mathrm{Hbs}$ are known to bind, transport, and/or react with several other ligands besides $\mathrm{O}_{2}$. For example, $\mathrm{Hbs}$ bind both $\mathrm{O}_{2}$ and carbon monoxide $(\mathrm{CO})$, but release $\mathrm{CO}$ much more slowly than $\mathrm{O}_{2}$. This competitive inhibition of $\mathrm{O}_{2}$ binding is the reason $\mathrm{CO}$ is a poisonous gas. LtEc can also bind $\mathrm{CO}$ and its subunits appear to have varying affinities (either high or low) for $\mathrm{CO}[58,59]$.

The interactions between $\mathrm{Hb}$ and $\mathrm{NO}$ have recently become crucially important with respect to HBOC development. Mammalian Hbs have been shown to catalyze a NO dioxygenation reaction in which $\mathrm{O}_{2}$ and $\mathrm{NO}$ react to form $\mathrm{NO}_{3}{ }^{-}$and metHb. The metHb increases oxidative stress, but the elimination of NO can have much more significant effects in vivo [60]. NO is a signaling molecule which regulates the diameter of blood vessels, relaxing them at high concentrations (vasodilation) and constricting them at low concentrations (vasoconstriction). Vasoconstriction also increases blood 
pressure and causes harmful systemic hypertension. Therefore, reducing NO dioxygenation is a high priority in HBOC design.

Mutagenesis studies in $\mathrm{HbA}$ have shown that mutations that reduce autoxidation also reduce the rate of NO dioxygenation. For example, substituting large apolar or aromatic residues (leucine, tryptophan, or phenylalanine) within the heme pocket or charged amino acids (glutamine) near the heme pocket entrance greatly reduces the rate of NO dioxygenation in oxy-HbA [60,61]. Both LtEc and AmEc have naturally occurring phenylalanine and tryptophan residues within their heme pockets [24,25]. There have not yet been any studies which focus specifically on the interactions between Ec's and NO, but there have been suggestions that Ec's may have a significantly reduced rate of $\mathrm{NO}$ dioxygenation relative to $\mathrm{HbA}[24,39,62]$. However, it is important to mention that these studies were not conclusive and more experiments must be done to determine the exact nature of the interactions between Ec's and NO.

\section{Availability and Economic Analysis of LtEc}

A wide array of different Ec's have been discovered with unique characteristics, such as extreme heat tolerance or $\mathrm{H}_{2} \mathrm{~S}$ transport $[36,63,64]$. However, since a large amount of Ec will be needed to meet the global demand for a RBC substitute, the host organism must be readily available. Most of the Ec's in the literature are extracted from deep sea worms, which may be difficult to grow at an industrial scale. Fortunately, LtEc is extracted from terrestrial earthworms which are readily available at a low cost ( $\$ 75 / 1,000$ earthworms) from many commercial sources. It is important to mention, however, that many different species of terrestrial earthworms have been discovered which might be grown as easily as L. terrestris. For example, the Ec of the Brazillian earthworm Glossoscolex paulistus (GpEc) has been extensively studied [65-72] and is an interesting alternative to LtEc that may also be commercially viable.

Any Ec product must also be ultrapure to be considered a viable HBOC candidate. The purification strategy used for Ec production must be efficient to keep the costs of the Ec product comparable to a unit of donated blood (estimates vary from \$200-\$1,000) [73]. A few different Ec purification processes have been developed, including ultracentrifugation [49], size exclusion chromatography (SEC) [40], and tangential flow filtration (TFF) [62]. Ultracentrifugation is simple and quick, but requires expensive equipment and may not produce ultrapure material. SEC produces ultrapure Ec, however, it is limited by low yields and is difficult to scale up. In contrast, TFF can easily produce large amounts of ultrapure LtEc (5-10 g/1,000 worms) and is easily scalable. Using the TFF LtEc yield, assuming a unit of donated human blood contains approximately $40-80$ grams of HbA, and omitting operational costs (which should be low for a TFF process), we can estimate that it would take at least 8,000 worms to produce a "unit" of LtEc with a cost of \$600 [62]. A more thorough economic analysis would be needed before producing any Ec on an industrial scale, but this estimate suggests that LtEc may be a slightly more expensive, yet affordable, alternative to donated blood.

\section{Preliminary Animal Studies with Ec's}

Preliminary experiments have been conducted in which small amounts of LtEc [40] and AmEc [39] have been injected into healthy mice and rats. AmEc quickly dissociated after mixing with plasma in 
vitro, but caused no noticeable side-effects in vivo and all animals were healthy 18 weeks after injection. In vitro experiments also indicated that $\mathrm{AmEc}$ is not scavenged by haptoglobin, a serum protein which strongly binds to free HbA and clears it from the bloodstream.

Injection of LtEc into mice and rats also lacked any side-effects. Most importantly, no immune response was observed even after repeated injections of LtEc [40]. We have also recently transfused small amounts $(0.5-1.5 \mathrm{~g} / \mathrm{dL})$ of LtEc into hamsters without any side-effects. In fact, we have observed that transfusion of LtEc causes slight vasodilation instead of the vasoconstriction caused by other HBOCs. These are only preliminary results, yet they suggest that LtEc may have a negligible rate of NO dioxygenation. LtEc also has a colloid osmotic pressure $(14 \mathrm{~mm} \mathrm{Hg})$ that is higher than some HBOCs (e.g., polymerized bovine Hb, 1-5 mm Hg), but similar to human whole blood (19-24 mm $\mathrm{Hg}$ ) [62]. Further studies with larger doses of LtEc will have to be done to accurately determine the efficacy and safety of LtEc, but all of the results presented here show that LtEc and other Ec's are intriguing class of HBOC.

\section{Conclusions}

Altogether, these results suggest that LtEc may be a superior HBOC, since it appears to avoid many of the problems associated with other HBOC's. It is highly stable, resistant to oxidation, and may have a negligible rate NO dioxygenation. It also has beneficial antioxidant properties which should minimize oxidative stress in vivo.

Despite all of the promising properties of LtEc, it is important to note that LtEc is still far away from clinical evaluation. Larger exchange transfusion studies need to be done in a series of animals (hamsters, guinea pigs, pigs, etc.) to determine if higher doses of LtEc pose any significant risks or side-effects. Since LtEc will be used in large doses, we must also determine the clearance mechanisms through which LtEc is eliminated in vivo to anticipate any toxic accumulation of heme or free iron. Models of hemorrhagic shock must also be used to simulate the effects of LtEc in emergency scenarios. In vitro, more work must be done to determine the exact nature of the interactions between $\mathrm{LtEc}$ and $\mathrm{NO}$ and other physiologically important ligands or effectors. The effects of $\mathrm{H}_{2} \mathrm{O}_{2}$ on LtEc oxidation and stability must also be determined to predict the effects of transfusing LtEc into patients with sepsis. The effects of storage conditions ( $\mathrm{pH}$, temperature, and buffer formulation) on LtEc must also be investigated to determine if/how LtEc can be kept for long periods of time. Once all of these questions are answered, human clinical trials with LtEc may begin.

\section{Acknowledgements}

This work was supported by National Institutes of Health grants R01HL078840 and R01DK070862 (to A.F.P). The images shown in Figure 1 were generated using the structural data for LtEc in the NCBI database (MMDB ID: 40482) from W.E. Royer, Jr.

\section{References}

1. Greenburg, A.G.; Kim, H.W. Hemoglobin-based oxygen carriers. Crit. Care 2004, 8, S61-S64. 
2. Cheng, D.C.; Mazer, C.D.; Martineau, R.; Ralph-Edwards, A.; Karski, J.; Robblee, J.; Finegan, B.; Hall, R.I.; Latimer, R.; Vuylsteke, A. A phase II dose-response study of hemoglobin raffimer (Hemolink) in elective coronary artery bypass surgery. J. Thorac. Cardiovasc. Surg. 2004, 127, 79-86.

3. Winslow, R.M. Red cell substitutes. Semin. Hematol. 2007, 44, 51-59.

4. Caron, A.; Menu, P.; Faivre-Fiorina, B.; Labrude, P.; Alayash, A.I.; Vigneron, C. Cardiovascular and hemorheological effects of three modified human hemoglobin solutions in hemodiluted rabbits. J. Appl. Physiol. 1999, 86, 541-548.

5. Kasper, S.M.; Grune, F.; Walter, M.; Amr, N.; Erasmi, H.; Buzello, W. The effects of increased doses of bovine hemoglobin on hemodynamics and oxygen transport in patients undergoing preoperative hemodilution for elective abdominal aortic surgery. Anesth. Analg. 1998, 87, 284-291.

6. Levy, J.H.; Goodnough, L.T.; Greilich, P.E.; Parr, G.V.; Stewart, R.W.; Gratz, I.; Wahr, J.; Williams, J.; Comunale, M.E.; Doblar, D.; et al. Polymerized bovine hemoglobin solution as a replacement for allogeneic red blood cell transfusion after cardiac surgery: Results of a randomized, double-blind trial. J. Thorac. Cardiovasc. Surg. 2002, 124, 35-42.

7. Lamuraglia, G.M.; O'hara, P.J.; Baker, W.H.; Naslund, T.C.; Norris, E.J.; Li, J.; Vandermeersch, E. The reduction of the allogenic transfusion requirement in aortic surgery with a hemoglobin-based solution. J. Vasc. Surg. 2000, 31, 299-308.

8. Sprung, J.; Kindscher, J.D.; Wahr, J.A.; Levy, J.H.; Monk, T.G.; Moritz, M.W.; O’hara, P.J. The use of bovine hemoglobin glutamer-250 (Hemopure) in surgical patients: Results of a multicenter, randomized, single-blinded trial. Anesth. Analg. 2002, 94, 799-808.

9. Vandegriff, K.D.; Malavalli, A.; Wooldridge, J.; Lohman, J.; Winslow, R.M. MP4, a new nonvasoactive PEG-Hb conjugate. Transfusion 2003, 43, 509-516.

10. Vandegriff, K.D.; Young, M.A.; Keipert, P.E.; Winslow, R.M. The safety profile of Hemospan ${ }^{\circledR}$ : A new oxygen therapeutic designed using maleimide poly(ethylene) glycol conjugation to human hemoglobin. Transfus. Altern. Transfus. Med. 2007, 9, 213-225.

11. Vandegriff, K.D.; Winslow, R.M. Hemospan: Design principles for a new class of oxygen therapeutic. Artif. Organs 2009, 33, 133-138.

12. Vandegriff, K.D.; Malavalli, A.; Minn, C.; Jiang, E.; Lohman, J.; Young, M.A.; Samaja, M.; Winslow, R.M. Oxidation and haem loss kinetics of poly(ethylene glycol)-conjugated haemoglobin (MP4): Dissociation between in vitro and in vivo oxidation rates. Biochem. J. 2006, 399, 463-471.

13. Natanson, C.; Kern, S.J.; Lurie, P.; Banks, S.M.; Wolfe, S.M. Cell-free hemoglobin-based blood substitutes and risk of myocardial infarction and death: A meta-analysis. J. Am. Med. Assoc. 2008, 299, 2304-2312.

14. Yubisui, T.; Matsuki, T.; Tanishima, K.; Takeshita, M.; Yoneyama, Y. NADPH-flavin reductase in human erythrocytes and the reduction of methemoglobin through flavin by the enzyme. Biochem. Biophys. Res. Commun. 1977, 76, 174-182.

15. Kuma, F. Properties of methemoglobin reductase and kinetic study of methemoglobin reduction. J. Biol. Chem. 1981, 256, 5518-5523.

16. Scott, M.D.; Lubin, B.H.; Zuo, L.; Kuypers, F.A. Erythrocyte defense against hydrogen peroxide: Preeminent importance of catalase. J. Lab. Clin. Med. 1991, 118, 7-16. 
17. Liu, X.; Miller, M.J.; Joshi, M.S.; Sadowska-Krowicka, H.; Clark, D.A.; Lancaster, J.R., Jr. Diffusionlimited reaction of free nitric oxide with erythrocytes. J. Biol. Chem. 1998, 273, 18709-18713.

18. Bunn, H.F.; Briehl, R.W. The interaction of 2,3-diphosphoglycerate with various human hemoglobins. J. Clin. Invest. 1970, 49, 1088-1095.

19. Chiancone, E. Dissociation of hemoglobin into subunits. II. Human oxyhemoglobin: Gel filtration studies. J. Biol. Chem. 1968, 243, 1212-1219.

20. Terwilliger, R.C. Structures of invertebrate hemoglobins. Am. Zool. 1980, 20, 53-67.

21. Boffi, A.; Verzili, D.; Chiancone, E.; Leone, M.; Cupane, A.; Militello, V.; Vitrano, E.; Cordone, L.; Yu, W.; di Iorio, E.E. Stereodynamic properties of the cooperative homodimeric Scapharca inaequivalvis hemoglobin studied through optical absorption spectroscopy and ligand rebinding kinetics. Biophys. J. 1994, 67, 1713-1723.

22. Di Iorio, E.; Tavernelli, I.; Yu, W. Dynamic properties of monomeric insect erythrocruorin III from Chironomus thummi-thummi: Relationships between structural flexibility and functional complexity. Biophys. J. 1997, 73, 2742-2751.

23. Zal, F.; Lallier, F.H.; Wall, J.S.; Vinogradov, S.N.; Toulmond, A. The multi-hemoglobin system of the hydrothermal vent tube worm Riftia pachyptila. I. Reexamination of the number and masses of its constituents. J. Biol. Chem. 1996, 271, 8869-8874.

24. Royer, W.E., Jr.; Sharma, H.; Strand, K.; Knapp, J.E.; Bhyravbhatla, B. Lumbricus erythrocruorin at 3.5 A resolution: Architecture of a megadalton respiratory complex. Structure 2006, 14, 1167-1177.

25. Royer, W.E.; Omartian, M.N.; Knapp, J.E. Low resolution crystal structure of Arenicola erythrocruorin: Influence of coiled coils on the architecture of a megadalton respiratory protein. J. Mol. Biol. 2007, 365, 226-236.

26. Terwilliger, N.; Terwilliger, R.C. Oxygen binding domains of a clam (Cardita borealis) extracellular hemoglobin. Biochim. Biophys. Acta 1978, 537, 77-85.

27. Xu, Y.; Zheng, Y.; Fan, J.-S.; Yang, D. A new strategy for structure determination of large proteins in solution without deuteration. Nat. Methods 2006, 3, 931-937.

28. Royer, W.E. J.; Strand, K.; van Heel, M.; Hendrickson, W.A. Structural hierarchy in erythrocruorin, the giant respiratory assemblage of annelids. Proc. Natl. Acad. Sci. USA 2000, 97, 7101-7111.

29. Strand, K.; Knapp, J.E.; Bhyravbhatla, B.; Royer, W.E., Jr. Crystal structure of the hemoglobin dodecamer from Lumbricus erythrocruorin: Allosteric core of giant annelid respiratory complexes. J. Mol. Biol. 2004, 344, 119-134.

30. Fushitani, K.; Matsuura, M.S.; Riggs, A.F. The amino acid sequences of chains a, b, and c that form the trimer subunit of the extracellular hemoglobin from Lumbricus terrestris. J. Biol. Chem. 1988, 263, 6502-6517.

31. Xie, Q.; Donahue, R.A., Jr.; Schneider, K.; Mirza, U.A.; Haller, I.; Chait, B.T.; Riggs, A.F. Structure of chain d of the gigantic hemoglobin of the earthworm. Biochim. Biophys. Acta 1997, 1337, 241-247.

32. Suzuki, T.; Riggs, A.F. Linker chain L1 of earthworm hemoglobin. Structure of gene and protein: Homology with low density lipoprotein receptor. J. Biol. Chem. 1993, 268, 13548-13555. 
33. Kao, W.Y.; Qin, J.; Fushitani, K.; Smith, S.S.; Gorr, T.A.; Riggs, C.K.; Knapp, J.E.; Chait, B.T.; Riggs, A.F. Linker chains of the gigantic hemoglobin of the earthworm Lumbricus terrestris: Primary structures of linkers L2, L3, and L4 and analysis of the connectivity of the disulfide bonds in linker L1. Proteins 2006, 63, 174-187.

34. Sharma, P.K.; Kuchumov, A.R.; Chottard, G.; Martin, P.D.; Wall, J.S.; Vinogradov, S.N. The role of the dodecamer subunit in the dissociation and reassembly of the hexagonal bilayer structure of Lumbricus terrestris hemoglobin. J. Biol. Chem. 1996, 271, 8754-8762.

35. Lamy, M.L.; Daily, E.K.; Brichant, J.F.; Larbuisson, R.P.; Demeyere, R.H.; Vandermeersch, E.A.; Lehot, J.J.; Parsloe, M.R.; Berridge, J.C.; Sinclair, C.J.; et al. Randomized trial of diaspirin cross-linked hemoglobin solution as an alternative to blood transfusion after cardiac surgery. The DCLHb cardiac surgery trial collaborative group. Anesthesiology 2000, 92, 646-656.

36. Numoto, N.; Nakagawa, T.; Kita, A.; Sasayama, Y.; Fukumori, Y.; Miki, K. Structure of an extracellular giant hemoglobin of the gutless beard worm Oligobrachia mashikoi. Proc. Natl. Acad. Sci. USA 2005, 102, 14521-14526.

37. Lamy, J.; Kuchumov, A.R.; Taveau, J.C.; Vinogradov, S.N.; Lamy, J.N. Reassembly of Lumbricus terrestris hemoglobin: A study by matrix-assisted laser desorption/ionization mass spectrometry and 3D reconstruction from frozen-hydrated specimens. J. Mol. Biol. 2000, 298, 633-647.

38. Birukou, I.; Soman, J.; Olson, J.S. Blocking the gate to ligand entry in human hemoglobin. J. Biol. Chem. 2011, 286, 10515-10529.

39. Rousselot, M.; Delpy, E.; Drieu La Rochelle, C.; Lagente, V.; Pirow, R.; Rees, J.F.; Hagege, A.; Le Guen, D.; Hourdez, S.; Zal, F. Arenicola marina extracellular hemoglobin: A new promising blood substitute. Biotechnol. J. 2006, 1, 333-345.

40. Hirsch, R.E.; Jelicks, L.A.; Wittenberg, B.A.; Kaul, D.K.; Shear, H.L.; Harrington, J.P. A first evaluation of the natural high molecular weight polymeric Lumbricus terrestris hemoglobin as an oxygen carrier. Artif. Cells Blood Substit. Immobil. Biotechnol. 1997, 25, 429-444.

41. Zapletal, C.; Bode, A.; Lorenz, M.W.; Gebhard, M.M.; Golling, M. Effects of hemodilution with a hemoglobin-based oxygen carrier (HBOC-201) on ischemia/reperfusion injury in a model of partial warm liver ischemia of the rat. Microvasc. Res. 2009, 78, 386-392.

42. Standley, P.; Mainwaring, M.G.; Gotoh, T.; Vinogradov, S.N. The calcium, copper and zinc content of some annelid extracellular haemoglobins. Biochem. J. 1988, 249, 915-916.

43. Harrington, J.P. Multimeric Lumbricus hemoglobin stabilization by alkali and alkaline earth cations. Comp. Biochem. Physiol. Part A 1994, 109, 799-803.

44. Chiancone, E.; Vecchini, P.; Rossi Fanelli, M.R.; Antonini, E. Studies on erythrocruorin. II. Dissociation of earthworm erythrocruorin. J. Mol. Biol. 1972, 70, 73-76.

45. Smith, M.L.; Paul, J.; Ohlsson, P.I.; Paul, K.G. The spontaneous hemin release from Lumbricus terrestris hemoglobin. Comp. Biochem. Physiol. Part A 1997, 118, 1241-1245.

46. Fushitani, K.; Imai, K.; Riggs, A.F. Oxygenation properties of hemoglobin from the earthworm, Lumbricus terrestris. Effects of pH, salts, and temperature. J. Biol. Chem. 1986, 261, 8414-8423.

47. Ochiai, T.; Weber, R.E. Effects of magnesium and calcium on the oxygenation reaction of erythrocruorin from the marine polychaete Arenicola marina and the terrestrial oligochaete Lumbricus terrestris. Zool. Sci. 2002, 19, 999-1000. 
48. Vidugiris, G.; Harrington, J.P.; Friedman, J.M.; Hirsch, R.E. Absence of ligand binding-induced tertiary changes in the multimeric earthworm Lumbricus terrestris hemoglobin. A resonance Raman study. J. Biol. Chem. 1993, 268, 26190-26192.

49. Fushitani, K.; Riggs, A.F. The extracellular hemoglobin of the earthworm, Lumbricus terrestris. Oxygenation properties of isolated chains, trimer, and a reassociated product. J. Biol. Chem. 1991, 266, 10275-10281.

50. Alayash, A.I. Hemoglobin-based blood substitutes and the hazards of blood radicals. Free Radic. Res. 2000, 33, 341-348.

51. Stellwagen, E. Haem exposure as the determinate of oxidation-reduction potential of haem proteins. Nature 1978, 275, 73-74.

52. Gow, A.J.; Payson, A.P.; Bonaventura, J. Invertebrate hemoglobins and nitric oxide: How heme pocket structure controls reactivity. J. Inorg. Biochem. 2005, 99, 903-911.

53. Harrington, J.P.; Kobayashi, S.; Dorman, S.C.; Zito, S.L.; Hirsch, R.E. Acellular invertebrate hemoglobins as model therapeutic oxygen carriers: Unique redox potentials. Artif. Cells Blood Substit. Immobil. Biotechnol. 2007, 35, 53-67.

54. Dorman, S.C.; Kenny, C.F.; Miller, L.; Hirsch, R.E.; Harrington, J.P. Role of redox potential of hemoglobin-based oxygen carriers on methemoglobin reduction by plasma components. Artif. Cells Blood Substit. Immobil. Biotechnol. 2002, 30, 39-51.

55. Dorman, S.C.; Harrington, J.P.; Martin, M.S.; Johnson, T.V. Determination of the formal reduction potential of Lumbricus terrestris hemoglobin using thin layer spectroelectrochemistry. J. Inorg. Biochem. 2004, 98, 185-188.

56. Harnois, T.; Rousselot, M.; Rogniaux, H.; Zal, F. High-level production of recombinant Arenicola marina globin chains in Escherichia coli: A new generation of blood substitute. Artif. Cells Blood Substit. Immobil. Biotechnol. 2009, 37, 106-116.

57. Liochev, S.I.; Kuchumov, A.R.; Vinogradov, S.N.; Fridovich, I. Superoxide dismutase activity in the giant hemoglobin of the earthworm, Lumbricus terrestris. Arch. Biochem. Biophys. 1996, 330, 281-284.

58. Giacometti, G.M.; Focesi, A., Jr.; Brunori, M.; Wyman, J. Effect of light on carbon monoxide binding by erythrocruorin. J. Biol. Chem. 1975, 98, 333-339.

59. Giacometti, G.M.; Focesi, A.; Giardina, B.; Brunori, M.; Wyman, J. Kinetics of binding of carbon monoxide to lumbricus erythrocruorin: A possible model. Proc. Natl. Acad. Sci. USA 1975, 72, 4313-4316.

60. Eich, R.; Li, T.; Lemon, D.D.; Doherty, D.H.; Curry, S.; Aitken, J.F.; Johnson, K.A.; Smith, R.D.; Phillips, G.N., Jr.; Olson, J.S. Mechanism of NO-induced oxidation of myoglobin and hemoglobin. Biochemistry 1996, 35, 6976-6983.

61. Olson, J.S.; Eich, R.F.; Smith, L.P.; Warren, J.J.; Knowles, B.C. Protein engineering strategies for designing more stable hemoglobin-based blood substitutes. Artif. Cells Blood Substit. Immobil. Biotechnol. 1997, 25, 227-241.

62. Elmer, J.; Zorc, K.; Rameez, S.; Zhou, Y.; Cabrales, P.; Palmer, A.F. Hypervolemic infusion of Lumbricus terrestris erythrocruorin purified by tangential flow filtration. Transfusion 2012, in press. 
63. Santiago, P.S.; Carvalho, J.W.; Domingues, M.M.; Santos, N.C.; Tabak, M. Thermal stability of extracellular hemoglobin of Glossoscolex paulistus: Determination of activation parameters by optical spectroscopic and differential scanning calorimetric studies. Biophys. Chem. 2010, 152, $128-138$.

64. Hourdez, S.; Weber, R.E. Molecular and functional adaptations in deep-sea hemoglobins. J. Inorg. Biochem. 2005, 99, 130-141.

65. Bachega, J.F.R.; Bleicher, L.; Horjales, E.R.; Santiago, P.S.; Garratt, R.C.; Tabak, M. Crystallization and preliminary structural analysis of the giant haemoglobin from Glossoscolex paulistus at 3.2 A. J. Synchrotron Radiat. 2010, 18, 24-28.

66. Poli, A.L.; Moreira, L.M.; Hidalgo, A.A.; Imasato, H. Autoxidation studies of extracellular hemoglobin of Glossoscolex paulistus at $\mathrm{pH}$ 9: Cyanide and hydroxyl effect. Biophys. Chem. 2005, 114, 253-260.

67. Poli, A.L.; Moreira, L.M.; Imasato, H. Autoxidation of giant extracellular hemoglobin of Glossoscolex paulistus: Molecular mechanism and oligomeric implications. Spectrochim. Acta A 2011, 82, 306-315.

68. Agustinho, S.C.; Tinto, M.H.; Imasato, H.; Tominaga, T.T.; Perussi, J.R.; Tabak, M. Spectroscopic studies of the met form of the extracellular hemoglobin from Glossoscolex paulistus. Biochim. Biophys. Acta 1996, 1298, 148-158.

69. Bispo, J.A.; Santos, J.L.; Landini, G.F.; Goncalves, J.M.; Bonafe, C.F. pH dependence of the dissociation of multimeric hemoglobin probed by high hydrostatic pressure. Biophys. Chem. 2007, $125,341-349$.

70. Moreira, L.M.; Poli, A.L.; Lyon, J.P.; Saade, J.; Costa-Filho, A.J.; Imasato, H. Ferric species of the giant extracellular hemoglobin of Glossoscolex paulistus as function of $\mathrm{pH}$ : An EPR study on the irreversibility of the heme transitions. Comp. Biochem. Physiol. B 2008, 150, 292-300.

71. Cardillo, F.; de Paula, E.; Oliveira, G.R.; Marangoni, S.; Oliviera, B.; Meirelles, N.C. Erythrocruorin of Glossoscolex paulistus (Oligochaeta, Glossoscolecidae): Modulation of oxygen affinity by specific antibodies. Biochem. Mol. Biol. Int. 1997, 41, 497-509.

72. Bonafe, C.F.; Villas-Boas, M.; Suarez, M.C.; Silva, J.L. Reassembly of a large multisubunit protein promoted by nonprotein factors. Effects of calcium and glycerol on the association of extracellular hemoglobin. J. Biol. Chem. 1991, 266, 13210-13216.

73. Shander, A.; Hofmann, A.; Gombotz, H.; Theusinger, O.M.; Spahn, D.R. Estimating the cost of blood: Past, present, and future directions. Best Pract. Res. Clin. Anaesthesiol. 2007, 21, 271-289.

(C) 2012 by the authors; licensee MDPI, Basel, Switzerland. This article is an open access article distributed under the terms and conditions of the Creative Commons Attribution license (http://creativecommons.org/licenses/by/3.0/). 